\title{
A young man with exertional chest discomfort
}

\author{
L. E. Lezcano Gort · B. Roque Rodríguez · M. R. Porro Fernández
}

Published online: 11 April 2019

(C) The Author(s) 2019

In this case we present a 43-year-old athletic male, nonprofessional cyclist with unremarkable medical history. He had been admitted to the emergency department because of chest discomfort, dizziness, heavy sweating and nausea after cycling $40 \mathrm{~km}$ in extreme heat (local temperature 41.5 degrees Celsius). Physical examination revealed a Glasgow Coma Scale score of 15, and he was haemodynamically stable. The laboratory results showed: creatine kinase $870 \mathrm{IU} / 1$, creatine kinase-MB $12 \mathrm{IU} / \mathrm{l}$, troponin $\mathrm{T} 16 \mathrm{ng} / \mathrm{ml}$, and creatinine $1.6 \mathrm{mg} / \mathrm{dl}$. Out-of-hospital electrocardiogram taken at first medical contact is shown in Fig. 1.
1. What is your diagnosis?

2. What is the most likely mechanism and the suggested therapy?

\section{Answer}

You will find the answer elsewhere in this issue.

Open Access This article is distributed under the terms of the Creative Commons Attribution 4.0 International License (http://creativecommons.org/licenses/by/4.0/), which permits unrestricted use, distribution, and reproduction in any medium, provided you give appropriate credit to the original author(s) and the source, provide a link to the Creative Commons license, and indicate if changes were made.

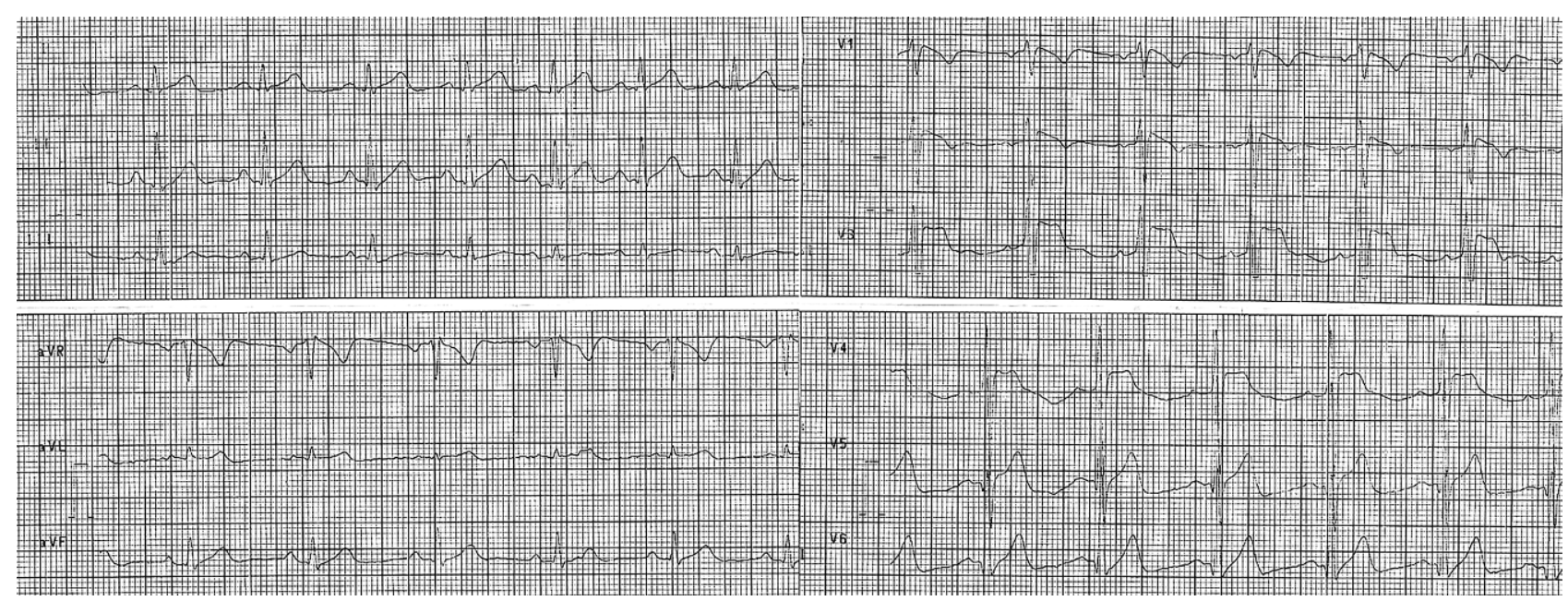

Fig. 1 Out-of-hospital electrocardiogram at first medical contact

L. E. Lezcano Gort $(\bowtie) \cdot$ B. Roque Rodríguez $\cdot$ M. R. Porro

Fernández

Department of Cardiology, San Pedro de Alcantara

Universitary Hospital, Cáceres, Spain

lezcanogort@gmail.com 